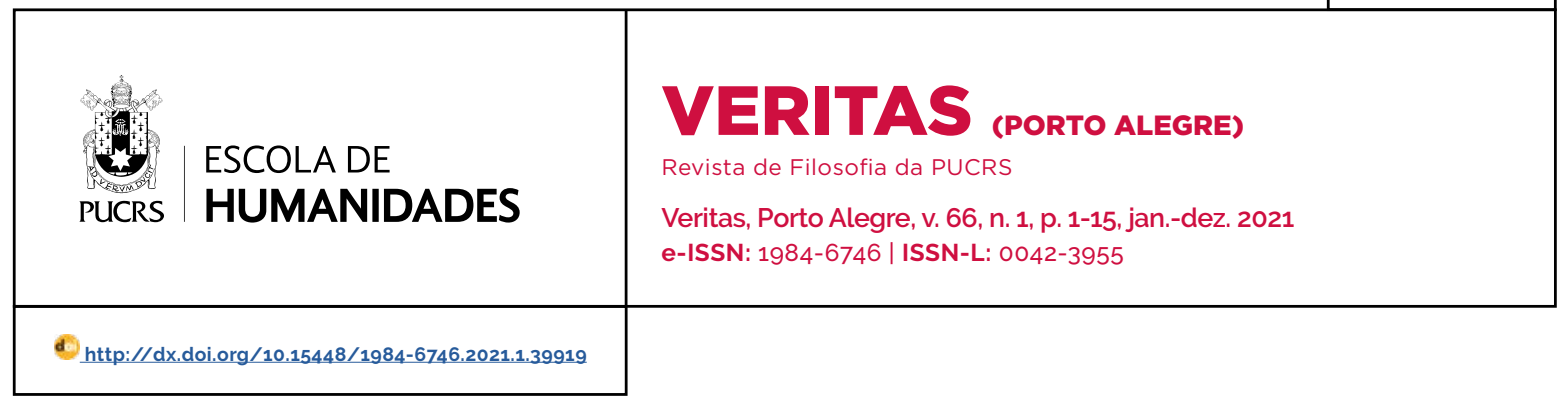

SEÇÃO: DOSSIÊ MORAL POLITICAL PHILOSOPHY

\title{
Ubuntu como filosofia moral?
}

\author{
¿Ubuntu cómo filosofía moral? \\ Ubuntu as a moral philosophy?
}

\section{Fabricio Pereira da \\ Silva ${ }^{1}$}

orcid.org/0000-0002-0266-4084

fabriciopereira31@gmail.com

Recebido em: 15 jan. 2021.

Aprovado em: 27 mar. 2021.

Publicado em: 11 maio 2021.
Resumo: Este artigo discute diferentes usos do ubuntu. Em particular, debate as possibilidades de o conceito atuar enquanto uma filosofia moral. Trata-se de uma discussão forte especialmente na academia sul-africana, e basicamente se divide entre os entusiastas do ubuntu como possibilidade de resgatar um senso de comunidade perdido; e seus detratores, que o entendem como incompativel com a modernidade.

Palavras-chave: Ubuntu. filosofia moral. Filosofia política. África do Sul.

Resumen: Ese artículo discute distintos usos del ubuntu. Particularmente, debate las posibilidades del concepto convertirse en una filosofía moral. Se trata de una discusión fuerte especialmente en la academia sudafricana, y básicamente se divide entre los entusiastas del ubuntu como posibilidad de rescatar un sentimiento de comunidad perdido; y sus detractores, que lo entienden como incompatible con la modernidad.

Palabras clave: Ubuntu. Filosofia moral. Filosofia política. Sudáfrica.

Abstract: This article discusses different uses of ubuntu. Particularly, it debates the possibilities for the concept to sustain a moral philosophy. It is a strong issue, especially in the South African academy, and this discussion is basically divided among ubuntu "enthusiasts" as a possibility to rescue a lost sense of community; and its "detractors", who understand it as incompatible with modernity.

Keywords: Ubuntu. Moral philosophy. Political philosophy. South Africa.

\section{Introdução}

Ubuntu, expressão das línguas xhosa e zulu, ${ }^{2}$ tem sido uma das noções mais recorrentes nos debates sobre África e os negro-africanos nas últimas décadas. Ubuntu parece adquirir progressivamente mais usos e sentidos, assumindo caracteristicas de um "conceito ônibus" [catch-all concept] (HAILEY, 2008). Revisando o que se produziu sobre a noção, percebe-se que compreender o seu significado e avaliar as suas potencialidades se tornou um problema para um número crescente de acadêmicos, políticos e ativistas.

Aqui interessa particularmente investigar os debates acadêmicos sobre o ubuntu, em particular nos campos da filosofia moral e política. O artigo lida com uma pergunta recorrente nas discussões acadêmicas, em particular da África do Sul (o seu principal espaço de discussões e 
de divulgação): ubuntu poderia sustentar uma filosofia moral? Se ele se baseia numa "visão de mundo" ainda recorrente no Sul da África, poderia se extrair dele uma ética particular, poderia ele sustentar preceitos morais úteis para a estruturação de uma sociedade melhor (inclusive para além de seu espaço geográfico de origem)? Como se verá, neste caso uma sociedade "melhor" implicaria na (re)valorização da comunidade, da solidariedade e dos laços sociais.

Para localizar minimamente as origens e a polissemia implicada na ideia de ubuntu, é necessário realizar uma breve história do conceito (apontando suas mudanças de sentido); e remeter ao momento de sua maior expansão que foi o fim da política de apartheid na África do Sul, desde então o centro principal de formulação e divulgação política e acadêmica do ubuntu. ${ }^{3}$

Deve-se observar que ubuntu é apenas uma entre diversas expressões oriundas de linguas do tronco linguístico bantu que vêm sendo retomadas contemporaneamente - tendo sido a que mais se popularizou. Há diversos outros termos com sentidos considerados assemelhados por especialistas: umunthu (chewa), umundu (yawo), bunhu (tsonga), unhu/hunhu (shona), botho (sotho e tswana), umuntu (zulu), vhutu (venda), vumunhu (changani), utu (swahili), entre muitos outros (TAMBULASI; KAYUNI, 2009; MAWERE; VAN STAN, 2016). Não surpreende que termos que expressam uma concepção comunitária das relações entre as pessoas se acumulem em distintas linguas da África Austral, Central e Oriental, na medida em que quase sempre constituiam sociedades comunais. Entre todas essas expressões, ubuntu foi a que assumiu circulação global, provavelmente por ser a utilizada no zulu e no xhosa. Trata-se das duas principais linguas de origem negra faladas na África do Sul, que foi seu principal centro de disseminação para o mundo. O papel de potência política, econômica e científica regional exercido pelo país deve ajudar a explicar a acelerada circulação do conceito.
O artigo se estrutura da seguinte forma. A primeira parte aborda as origens do conceito de ubuntu, e aponta a sua crescente associação ao que se convencionou chamar na filosofia africana de "etnofilosofia": haveria uma essencial visão de mundo (Weltanschauung), uma ética própria que perpassaria todos os povos africanos. A segunda parte trata do principal foco de expansão contemporânea do conceito: os usos do ubuntu na transição do apartheid sul-africano, particularmente na Constituição Interina e na Comissão da Verdade e Reconciliação (Truth and Reconciliation Comission, TRC). A terceira parte aborda os debates filosóficos em torno do tema, divididos entre os "entusiastas" e os "detratores" do ubuntu: os que nele buscam potência transformadora, por seu pretenso potencial de informar uma moral alternativa de ênfase coletiva, comunal, solidária; e os que nele identificam apenas mistificação, tradicionalismo e opressão de indivíduos e de minorias. Finalmente, a última seção reflete sobre a modernidade do ubuntu, ou expressado de outro modo, até que ponto ele poderia ser considerado uma passadista "narrativa de retorno" - inviável como fonte de transformações na contemporaneidade.

\section{Os primeiros usos do ubuntu e os seus significados mais recorrentes}

Não é a intenção deste artigo apresentar uma história do conceito do ubuntu, mas é importante apontar algumas de suas tendências de desenvolvimento. ${ }^{4}$ Segundo Gade (2011), o uso do ubuntu em textos escritos pode ser mapeado desde ao menos 1846. Até meados do século $X X$, os seus principais sentidos giraram em torno de "natureza humana" (human nature), "humanidade" (humanity), "homem adulto" (manhood), e da expressão de mais dificil tradução para o português: humanness, que poderia ser entendida como "fazer-se humano", o "ato de humanizar-se", o "processo de humanização". Em suma, desde o princípio o ubuntu esteve relacionado a uma qualidade moral ("alguém tem ubuntu"). Porém, já em boa parte dos

\footnotetext{
3 Deve-se mencionar que ubuntu e termos assemelhados vêm sendo utilizados, ainda que em menor escala, também em outros países da região, como Zimbabwe, Malawi, Botswana e Ruanda.

4 Para esforços meus neste sentido, conferir Silva (2020, 2021).
} 
primeiros textos que o mencionaram, seria uma qualidade que se expressaria primordialmente entre os negros africanos, entre os bantu, entre os "indigenas" - ideia que se imporia mais adiante.

A partir de meados do século XX, o termo foi assumindo os sentidos que hoje são mais comuns. Resumidamente, foi sendo menos entendido como uma "qualidade moral" (ainda que essa noção se preserve), para assumir-se como um fenômeno mais amplo, mais sistêmico (e especificamente negro-africano ou bantu): seja uma "filosofia", uma "ética", um "humanismo", uma "visão de mundo". Nos anos 1970, ubuntu foi associado aos "humanismos africanos" e "socialismos africanos" que informaram os processos de descolonização e de construção de novos Estados, assumindo então usos mais claramente políticos. O conceito foi reapropriado politicamente durante a superação do apartheid que levou à eleição de Nelson Mandela na África do Sul em 1994. Naquele contexto, foi largamente entendido no campo político como "visão de mundo", e no acadêmico como uma "filosofia moral", uma "ética".

Como já foi dito, o foco central de desenvolvimento e divulgação do conceito vem sendo a África do Sul, desde o fim do apartheid. Naquele momento, o ubuntu parece ter se tornado para muitos políticos, ativistas, gestores e acadêmicos um elemento providencial para a unidade e para a formulação de políticas públicas, do que foi entendido como uma nova nação e um novo Estado em construção. Gade (2011) sugere que foi nesse periodo transicional da África do Sul, mais precisamente entre 1993 e 1995, que o ubuntu ganhou seus sentidos contemporaneamente hegemônicos. Trata-se principalmente de entendê-lo como uma "visão de mundo" particular, que pode ser definida a partir do provérbio zulu umuntu ngumuntu ngabantu - vagamente traduzido para o português como "uma pessoa é uma pessoa através de outras pessoas". O autor aponta que houve um incremento de referências sobre o ubuntu a partir da segunda metade dos anos 1990 e particularmente nos anos
2000; e que os seus cinco sentidos mencionados acima (qualidade humana, ética/filosofia moral, humanismo africano, visão de mundo e umuntu ngumuntu ngabantu) seguem vigentes contemporaneamente, ainda que com distintos impactos.

O filósofo Augustine Shutte teve papel importante na associação do ubuntu ao provérbio umuntu ngumuntu ngabantu, com o seu livro Philosophy for Africa [Filosofia para a África], publicado em 1993 na África do Sul, e em 1995 nos EUA5; bem como Desmond Tutu em No Future Without Forgiveness [Não há futuro sem perdão], publicado em 1999 e com imediata circulação global. O ubuntu, desde então também foi repetidamente associado a outra expressão de significado aproximado: "eu sou porque nós somos" ("I am because we are"), que também remeteria ao contexto bantu de solidariedade e família ampliada. É pouco mencionado que essa é uma citação da obra clássica de John Mbiti intitulada African Religions and Philosophy [Religiões Africanas e Filosofia], de 1969. Segundo Bell, o ubuntu

às vezes é referido como comunalismo africa-
no. Uma frase frequentemente citada do livro
amplamente lido de John Mbiti African Religions
and Philosophy (1969) apoiando esta visão é:
"eu sou porque nós somos, e desde que nós
somos então eu sou", reconhecimento como
jogo e inversão do bem conhecido cogito ergo
sum de Descartes, que identifica o eu com o "eu
sou" isoladamente do "nós somos" (2002, p. 59).

Portanto, a partir do que foi discutido até aqui, pode-se sugerir que ocorreram ao menos dois processos paralelos de desenvolvimento do conceito. O primeiro foi a sua complexificação, passando de qualidade humana a algo sistêmico - uma ética, filosofia, ideologia ou visão de mundo. O segundo processo foi a sua crescente associação ao negro-africano (em particular bantu), conectado ao seu modo de vida, à sua origem, à sua forma de relacionar-se com a comunidade (incluidos os ancestrais e as futuras gerações) e com a natureza. Esses dois desenvolvimentos se deram notadamente a partir de meados do século $X X$, e são a chave para compreender os

5 A associação entre o ubuntu e o provérbio aparece na edição de 1995. mas não na de 1993. Do mesmo modo, é só em 1995 (na edição norte-americana, portanto) que Shutte apresenta o seu livro explicitamente como uma obra sobre o ubuntu. Isso reforça a tese de Gade de que o periodo entre 1993 e 1995 foi essencial para o surgimento daqueles novos sentidos do ubuntu. 
usos do ubuntu desde os anos 1990 - associando-o a uma contribuição original (sul)africana ao fomento da comunidade, da solidariedade, do perdão, da unidade, da harmonia e da justiça.

Nesse sentido, para entender o desenvolvimento do conceito é útil recorrer ao que se convencionou chamar no debate da filosofia africana de "etnofilosofia", uma influência fundamental em sua constituição. A sua origem remonta às primeiras formulações do que seria propriamente uma filosofia africana. A etnofilosofia defende a unidade de modos de pensar, agir e sentir de todos os grupos sociais negro-africanos, geralmente marcados pela proeminência do grupo ou da comunidade sobre o individuo. Portanto, ela atribui uma "essência" ao negro-africano, mais ou menos constante ao longo do tempo e do espaço, que pode ser atribuida aos mais diversos fatores a depender do autor, como biológicos, ambientais, históricos, econômicos, sociais e culturais (MANGENA, 2016).

Um marco fundador dessas formulações foi a obra do padre belga Placide Tempels intitulada La Philosophie Bantoue [A Filosofia Bantu], de 1945, baseada em sua atuação como missionário no então Congo Belga (atual República Democrática do Congo). O termo "bantu" havia sido cunhado pelo filólogo e antropólogo alemão Wilhelm Heinrich Immanuel Bleek "em sua tese doutoral defendida em Bonn em 1851, pensando num parentesco de muitas línguas africanas do sul do Saara (África Central, Oriental e Austral)" (KASHINDI, 2013, p. 210). Com Tempels, a ideia de uma unicidade das culturas bantu foi elevada a novo patamar, a partir da proposição de que havia uma filosofia tradicional própria desses povos, calcada numa essência bantu - no limite, negro-africana. A ontologia bantu seria baseada na "força vital", o elemento que define o que é o ser ("quem possui a força"), que define a "pessoa" (o muntu, "aquela força vital dotada de inteligência e de vontade"). A força conectaria os homens com os outros seres vivos e inanimados, conectaria os viventes com os antepassados (ambos convivendo em comunidade no presente) e deveria ser transmitida às gerações futuras:
Para os bantu, todos os seres do universo possuem sua própria força vital; humano, animal, vegetal ou inanimado. Cada ser foi dotado por Deus com uma certa força, capaz de fortalecer a energia vital do ser mais forte da criação: o homem. A suprema felicidade, a única forma de felicidade é para os bantu a posse do maior poder vital; a pior adversidade e, de fato, o único aspecto do infortúnio, é para ele a diminuição desse poder. Toda doença, ferida ou aborrecimento, todo sofrimento, depressão ou fadiga, toda injustiça ou fracasso, é considerada e designada pelo bantu como uma diminuição da força vital (TEMPELS, 1945, p. 29).

A obra de Tempels foi a primeira a associar o negro à filosofia, a uma sabedoria, a um sistema de principios, e a uma Weltanschauung - então entendidas como expressões exclusivamente brancas, europeias, ocidentais. Ele teve larga repercussão entre estudiosos africanistas e africanos, e marcou a filosofia africana do periodo das descolonizações:

\begin{abstract}
No iniciante "mercado de ideias" sobre pensamento africano, a "filosofia bantu" de Tempels tornou-se um concorrente para o trono de " $\mathrm{A}$ " visão filosófica africana principal - ainda mantém uma certa qualidade magnética em relação a isso. O que veio a ser chamada de visão "animista" de mundo - que é frequentemente aplicada universal e indiscriminadamente a todos os padrões de pensamento africanos é rastreável, em parte, a Tempels e sua visão etnofilosófica (BELL, 2002, p. 23).
\end{abstract}

A busca por uma essência negro-africana positiva, que poderia contribuir para transformar um presente de alienação, individualismo e desencantamento, é contemporaneamente reativada por parte dos que recorrem ao ubuntu. veremos agora o momento preciso em que o ubuntu corporificou essa procura por uma originalidade africana através da sua ancestralidade.

\section{A visibilização: usos do ubuntu na transição sul-africana}

O termo ubuntu foi introduzido na Constituição Interina da África do Sul, ratificada em novembro de 1993 para servir de base legal na transição do apartheid à democracia. Nela, o conceito foi mencionado de forma vaga, sem ser definido, associado à necessidade de unidade nacional e reconciliação:

A adoção desta Constituição estabelece a base segura para o povo da África do Sul transcen- 
der as divisões e lutas do passado, que geraram graves violações de direitos humanos, a transgressão de princípios humanitários em violentos conflitos e um legado de ódio, medo, culpa e vingança. Isso pode ser agora abordado com base na necessidade de entendimento mas não de vingança, de reparação mas não de retaliação, de ubuntu mas não de vitimização (REPUBLIC OF SOUTH AFRICA, [1993])

O conceito terminou ausente da Constituição definitiva, promulgada em dezembro de 1996. No entanto, a Corte Constitucional vem desde então se valendo sistematicamente do ubuntu para justificar as suas interpretações, entendendo-o como um princípio basilar da Constituição e da sociedade sul-africana. Diversas decisões da Corte têm apontado o ubuntu como a base para uma jurisprudência "africana", ao mesmo tempo em harmonia com os valores ocidentais e contemporâneos que atravessam a Carta. ${ }^{6}$

Outra chave para a visibilidade que o conceito ganhou na transição sul-africana está no funcionamento da TRC. Esse foi o mecanismo inventado a partir da transição negociada para produzir conciliação e unidade nacional. A atuação de Tutu ao longo da transição sul-africana e como presidente da TRC merece particular destaque. Sugiro que a fixação da ideia de ubuntu como uma "visão de mundo" negro-africana e sua associação ao provérbio umuntu ngumuntu ngabantu passam em grande medida pelo arcebispo anglicano, ao longo de suas incontáveis entrevistas, sermões, vídeos, discursos e livros de divulgação global desde os anos 1990. O ubuntu seria uma forma de garantir a coesão de uma sociedade profundamente dividida e desigual, marcada pela violência e pela opressão, constituindo-se na possibilidade de convivência dos antigos opressores e oprimidos.

A ideia de que "uma pessoa é uma pessoa através de outras pessoas" foi largamente utilizada por Tutu em suas obras desde os anos 1990, como o elemento que deveria fornecer a base para a interdependência, insistindo na irmandade/ sororidade entre as pessoas e complementarmente na sacralidade de cada uma delas, uma unidade na diversidade - evitando desse modo comunitarismos ou individualismos extremados. Particularmente durante a TRC, Tutu exerceu papel importante na proposição de uma justiça "restaurativa" em lugar de "retributiva", sugerindo que a primeira estava inscrita nas tradições africanas e especificamente na ideia do ubuntu:

\begin{abstract}
justiça retributiva - na qual um Estado impessoal impõe uma punição com pouca consideração pelas vítimas e dificilmente alguma pelo perpetrador - não é a única forma de justiça. Defendo que há outro tipo de justiça, justiça restaurativa, que foi caracteristica da jurisprudência tradicional africana. Aqui a principal preocupação não é retribuição ou punição, mas, no espirito do ubuntu, a cura de violações, a correção de desequilibrios, a restauração de relações rompidas. Esse tipo de justiça busca reabilitar tanto a vítima quanto o perpetrador. a quem deve ser dada a oportunidade de ser reintegrado à comunidade que ele ou ela feriu com sua ofensa (TUTU, 1999, p. 51-52).
\end{abstract}

A justiça restaurativa foi a base da TRC, pensada como elemento central da pacificação, reconstrução e unificação do país. Funcionando de 1995 a 1998, ela constituiu-se numa das principais experiências de comissões da verdade, ao condicionar a oferta de anistia ao oferecimento de depoimento público por parte do requerente, no qual a principal exigência deveria ser "contar a verdade" sobre os crimes (cometidos entre 1960 e 1994) para os quais se solicitava anistia. O ponto mais elogiado no processo de anistia sul-africano foi sua condicionalidade, evitando, assim, a sua oferta geral (BURTON, 2016). O ponto mais contestado, por sua vez, foi a limitada reparação dos crimes, enfatizando-se a exposição pública dos violadores de direitos humanos e o registro e construção de uma memória coletiva.

Tutu é exemplar na divulgação de narrativas reunidas nas audiências públicas da TRC, insistindo na necessidade de "perdão, mas não de esqueci-

\footnotetext{
6 Isso vem recebendo apoio de defensores de uma adequação das leis e instituições sul-africanas à realidade local (cf. Ramose, 2003c): mas igualmente atrai criticas de especialistas que associam o ubuntu à tradição, à religião e ao passado, e com isso negam o seu lugar na contemporaneidade. Ilze Keevy (2009), por exemplo, afirma que o ubuntu sustenta estereótipos de "mulheres, crianças, homossexuais, lésbicas, bruxas, estrangeiros e outsiders [...] ubuntu não está em consonância com os valores da Constituição em geral e com a Declaração de Direitos em particular" (2009, p. 22). Para a autora, "em contraste com a lei ocidental, a lei africana é inseparável de sua base patriarcal, dos ancestrais e da solidariedade de grupo ou forte comunitarismo. A lei e a justiça ocidentais não propõem esses antigos ideais africanos e permanecem um conceito estrangeiro em sociedades africanas tradicionais" (2009. p. 30).
} 
mento". A TRC foi apresentada por ele como uma "terceira via" oferecida pela excepcionalidade (sul-) africana entre, num extremo, os Julgamentos de Nuremberg, que condenaram referentes nazistas e, num outro extremo, uma "amnésia nacional". Para isso, Tutu lançou mão da sua reflexão teológica marcada por uma leitura de esquerda do cristianismo, um cristianismo de libertação - tanto do opressor quanto do oprimido. É em bases teológicas que o autor justifica a sua militância contra o apartheid, entendido como blasfêmia: "Foi isso que levou alguns de nós com tanto comprometimento apaixonado a lutar por justiça e liberdade. Fomos inspirados não por motivos políticos, mas por nossa fé bíblica. A Bíblia acabou sendo o livro mais subversivo imaginável numa situação de injustiça e opressão" (TUTU, 1999, p. 11).

Se um dos pilares da formulação de Tutu é o cristianismo de libertação, o outro é a herança africana. A citação a seguir é longa, mas ilustrativa desse ponto:

essa terceira via de anistia condicional foi consistente com um elemento central da Weltanschauung africana (ou visão de mundo) - o que nós conhecemos como ubuntu no grupo de línguas nguni, ou botho nas linguas sotho. O que é isso que constrangeu tantos a escolherem por perdoar ao invés de demandarem retribuição, a serem tão magnânimos ao invés de buscarem vingança? Ubuntu é muito dificil de traduzir para uma língua ocidental. Ele fala da própria essência de ser humano. Quando nós queremos fazer um grande elogio a alguém nós dizemos, "Yu, u nobuntu"; "Ei, ele ou ela tem ubuntu". Isso significa que eles são generosos, hospitaleiros, amigáveis, cuidadosos e compassivos. Eles compartilham o que eles têm. Isso também significa que minha humanidade é associada, é inextricavelmente ligada à deles. Nós pertencemos a um feixe de vida. Nós dizemos, "uma pessoa é uma pessoa através de outras pessoas". Isso não é "penso logo existo". Se diz melhor: "eu sou humano porque eu pertenço". Eu participo, eu compartilho. Uma pessoa com ubuntu é aberta e disponivel aos outros, se afirma pelos outros, não se sente ameaçada se os outros são capazes e bons; ele ou ela tem uma garantia que vem de saber que ele ou ela pertence a um todo maior e é diminuido quando outros são humilhados ou diminuidos, quando outros são torturados ou oprimidos, ou tratados como se fossem menos do que são. Harmonia, simpatia, comunidade são grandes bens. Harmonia social é para nós o summum bonum - o maior bem. Tudo que subverte ou debilita esse procurado bem deve ser evitado como a praga. Raiva, ressentimento, desejo de vingança, mesmo o sucesso através de competitividade agressiva, são corrosivos desse bem. Perdoar não é só ser altruista. É a melhor forma de autointeresse. O que desumaniza você inexoravelmente me desumaniza. Perdoar dá às pessoas resiliência, permitindo-as sobreviver e emergir ainda humanas apesar de todos os esforços para desumanizá-las. Ubuntu significa que num sentido real mesmo os apoiadores do apartheid foram vitimas do sistema vicioso que eles implementaram e que eles apoiaram tão entusiasticamente. [...] o opressor foi desumanizado tanto, se não mais, que o oprimido (TUTU, 1999, p. 34-35).

Conectando os dois pilares mencionados acima, Tutu entende o ubuntu também como uma expressão de uma universal nostalgia por um paraíso perdido, oriunda da nossa expulsão do Jardim do Éden. Se a humanidade vivencia um processo centrifugo de alienação, desarmonia, desagregação, há uma divina força centrípeta que impele à comunidade, à reconciliação, à justiça, à unidade (em Cristo), que vem desde o "princípio dos tempos". Aqui pode-se localizar mais uma vez a mencionada dubiedade aparente que estaria na base do ubuntu: ele seria essencialmente (exclusivamente) africano, ou poderia ser expressado por toda a humanidade? Outro ponto importante é a forma como Tutu conecta o passado (a "nostalgia pelo paraíso perdido") ao futuro, ao afirmar que o movimento em direção à unidade (mediante o perdão) é a única garantia para haver futuro.

\section{Organizando o debate filosófico sobre o ubuntu}

Foi entre teóricos e filósofos políticos que se procurou definir o ubuntu de uma forma mais precisa. A partir desse debate, pode-se mapear os acadêmicos "simpáticos" e "críticos" ao uso do ubuntu. Vejamos alguns esforços em defini-lo, para em seguida apresentar o debate em torno da validade do conceito - o que se fará a partir da principal disputa acadêmica que se estabeleceu em torno do tema.

Para começar, faz-se necessário ir além de "uma pessoa é uma pessoa através de outras pessoas" e de "eu sou porque nós somos":

O ubuntu tem aspectos que vão além do conteúdo desses provérbios. Tem que ser discutido em um horizonte ontológico abrangente. 
Isto mostra como o be-ing ${ }^{7}$ de uma pessoa africana não está apenas imerso na comunidade, mas no universo como um todo. Isto é expresso principalmente no prefixo ubu- da palavra ubuntu. Refere-se ao universo como sendo envolvido, contendo tudo. O tronco -ntu significa o processo da vida como o desdobramento do universo através de manifestações concretas em diferentes formas e modos de ser. Este processo inclui o surgimento do ser humano falante e conhecedor. Como tal, este ser é chamado "umuntu" ou, na lingua Sotho do Norte, "motho", que é capaz de esforços para articular a experiência e o conhecimento do que é o ubu-. Assim, -ntu representa o lado epistemológico do ser (RAMOSE, 1999, p. 4952, apud KIMMERLE, 2006, p. 81-82).

Um ponto recorrente nas definições sobre o ubuntu passa por associá-lo em diferentes níveis à comunidade: ao comum, à solidariedade, à interdependência entre as pessoas (KIMMERLE, 2006; MUNYAKA; MOTLHABI, 2009). Shutte (2009) especifica que o conceito deveria ser associado à "comunidade", não a "coletivismo" - mais precisamente à concepção africana de comunidade. Ele afirma que tanto o individualismo quanto o coletivismo são duas concepções ocidentais, ambas calcadas numa visão artificial da sociedade como agregação de indivíduos. Difeririam entre elas apenas quanto ao peso atribuido ao individuo ou à sociedade. Já o ubuntu estaria associado ao comunalismo, contribuindo, por isso, para a superação da artificial dicotomia indivíduo/ sociedade. Ele poderia ser vagamente associado a um "organicismo", e mais precisamente à noção de "pessoa". Diferentemente de um organismo no qual cada órgão assume importância pelo que ele pode fazer de distinto em relação aos outros,

na concepção africana de comunidade cada parte é o mesmo - uma pessoa. A coisa importante sobre cada pessoa é o que elas têm em comum, nomeadamente que elas são pessoas. Mesmo que isso possa soar estranho, só se pode fazer justiça com a concepção africana de comunidade visualizando-a como uma única pessoa. Cada indivíduo está então relacionado com a comunidade não como uma parte do todo, mas como uma pessoa está relacionada com elas mesmas. Cada membro individual da comunidade vê a comunidade como eles mesmos, como um com eles em caráter e identidade (SHUTTE, 2009, p. 94, grifo do autor).
Para Shutte, o ubuntu é uma ética, é "a qualidade adquirida de humanidade que é característica de uma pessoa plenamente desenvolvida e da comunidade com outros dai resultante. Compreende então valores, atitudes, sentimentos, relacionamentos e atividades, o amplo espectro de expressões do espírito humano" (2009, p. 97). Para o autor, apesar de ser uma ética constituida sob condições socioeconômicas distintas da África do Sul contemporânea, ela não estaria restrita ao passado: ainda viveria no presente, como algo renovado, expresso em pessoas e modos de vida, em famílias e empreendimentos de diversos tipos. Desse modo, não representaria um retorno a uma mítica "era de ouro", mas algo novo a ser descoberto, que deve ser (re)construído e adaptado à modernidade, posto em contato com outras tradições éticas.

Por sua vez, Mogobe Ramose (2003a, 2003b) afirma que o ubuntu é a base da filosofia africana. Procura definir o termo a partir de uma densa análise etimológica e, dentre os autores que tratam do tema, é provavelmente o que mais procura se aproximar das suas raizes originais. A citação a seguir é longa, porém fundamental:

É melhor, filosoficamente, abordar este termo como uma palavra hifenizada, a saber, ubu-ntu. Ubuntu é na verdade duas palavras em uma. Consiste no prefixo ubu- e no radical ntuUbu- evoca a ideia de ser-sendo [be-ing] em geral. É o envolvido ser-sendo antes de se manifestar na forma concreta ou no modo de ex-istência de uma entidade particular. Ubu-como ser-sendo envolvido está sempre orientado para o desdobramento, ou seja, incessante manifestação concreta e contínua através de formas e modos particulares de ser. Nesse sentido, ubu- é sempre orientado em direção ao -ntu. No nível ontológico, não há separação e divisão estritas e literais entre ubu-e -ntu. Ubu-e -ntu não são duas realidades radicalmente separadas e irreconciliavelmente opostas. Pelo contrário, eles se fundam mutuamente no sentido de que são dois aspectos do ser-sendo como uma uni-cidade [one-ness] e uma total-idade [whole-ness] indivisivel. Por conseguinte, ubu-ntu é a categoria ontológica e epistemológica fundamental no pensamento africano dos povos de fala bantu. É a indivisivel uni-cidade e total-idade da ontologia e epistemologia. Ubu- como a compreensão generalizada de ser-sendo pode ser consi-

\footnotetext{
7 "Ser sendo", "existir através de". O hífen separando a palavra é sempre utilizado por Ramose (como em human-ness) para enfatizar que a construção do "eu" africano deve ser entendida como processo, como algo dinâmico.
} 
derado distintamente ontológico. Enquanto -ntu como o ponto nodal no qual o ser-sendo assume forma concreta ou um modo de estar no processo de contínuo desdobramento pode ser considerado distintamente epistemológico (RAMOSE, 2003a, p. 271). ${ }^{8}$

Desse modo,

ser um ser-sendo humano [human be-ing] é afirmar sua humanidade através do reconhecimento da humanidade dos outros e, nessa base, estabelecer relações humanas com eles. Ubuntu, entendido como fazer-se humano Ihumanness]; uma atitude humana, respeitosa e polida com os outros constitui o sentido central desse aforismo [umuntu ngumuntu nga bantu] (RAMOSE, 2003a, p. 272).

Ubuntu é um fazer-se humano, o autor enfatiza (human-ness), nunca uma ideologia, um "ismo" (human-ism). Também não se trata de "humanidade" (humanity) como defendido por Shutte (que segundo Ramose estaria buscando no conceito valores éticos passiveis de universalização a toda a humanidade, insights para uma vida melhor em comunidade). Ramose por sua vez reafirma a africanidade do conceito (logo, sua particularidade), e defende que é por causa do ubuntu que a religião, a política e a lei africanas visariam sempre a "harmonia cósmica" a ser obtida através do consenso: a paz através da realização da justiça.

Munyaradzi Felix Murove (2009) destaca a relacionalidade, a interdependência no ato de humanizar-se, no processo de humanização associado à concepção do ubuntu. Uma pessoa é uma pessoa a partir de outra pessoa na medida em que o processo de humanização é derivado da relacionalidade com os outros: alguém só se torna plenamente humano em contato com outras pessoas. O autor insiste na interconexão entre passado, presente e futuro - entre o imortal, o mortal e o que virá que atravessam o conceito. Essa conexão se dá exatamente através "dos valores morais que foram herdados, preservados e passados para as futuras gerações. Valores são imortais na medida em que promovem uma existência harmoniosa entre o passado, o presente e o futuro" (2009, p. 319). Murove destaca que a relação totêmica da geração do presente com os ancestrais (que são também parte do presente, nesse sentido, "mortos-vivos") leva a uma concepção integrada com o mundo natural, uma relacionalidade com o entorno derivada da necessidade de garantir recursos para que as futuras gerações possam seguir cultuando os ancestrais.

O debate em torno do ubuntu pode ser organizado, como sugerido por Eliastam, entre

\begin{abstract}
aqueles que argumentam que, como um principio fundacional da filosofia africana, ubuntu oferece possibilidades significantes para a transformação da sociedade sul-africana le eventualmente para além dela], le entrel aqueles que argumentam que ubuntu é vago, cheio de contradições, e sujeito a um uso manipulativo e mesmo nefasto (2015, p. 1).
\end{abstract}

Proponho exemplificar as duas posições a partir de um diálogo recente, desenvolvido no periódico South African Journal of Philosophy. Bernard Matolino e Wenceslaus Kwindingwi publicaram o artigo "The end of Ubuntu" IO fim do ubuntul em 2013, como um pesado ataque ao uso do conceito. Thaddeus Metz, filósofo político norte-americano radicado na África do Sul e um dos maiores defensores do uso contemporâneo do ubuntu, se considerou diretamente visado pelo artigo e publicou a réplica "Just the beginning for ubuntu: reply to Matolino and Kwindingwi" ISó o começo para o ubuntu: resposta a Matolino e Kwindingwil em 2014. Finalmente, Matolino escreveu a tréplica "A response to Metz's reply on the end of ubuntu" [Uma resposta para a resposta de

8 Com isso, Ramose inverte a clássica formulação do filósofo ruandês Alexis Kagame sobre a visão de mundo bantu formulada em sua tese de doutorado La philosophie Bantu-Rwandaise de l'Etre (A Filosofia Bantu-Ruandense do Ser, de 1955). Para esse autor, que buscou aprofundar, a partir da própria perspectiva africana, o estudo de Tempels, -ntu era a força universal cósmica. Como se viu, para Ramose o conceito com maior nivel de generalidade em ubu-ntu (o que remete à ontologia) seria ubu-, enquanto -ntu estaria associado à concretude (à epistemologia). 
Metz sobre o fim do ubuntu] em 2015. ${ }^{9}$ Vejamos a argumentação de cada um.

No primeiro artigo, Matolino e Kwindingwi afirmam a inviabilidade do ubuntu, seja como ideologia ou inspiração ética, em ambos os casos por sua inadequação à modernidade:

(1) através de uma análise das narrativas de retorno procuramos mostrar que o ubuntu como ideologia não está bem enraizado nas experiências éticas de pessoas modernas como seres morais; e (2) procuramos argumentar que o ubuntu como solução ética concebida carece de capacidade e de contexto para ser uma inspiração ou código de ética no presente (2013, p. 198).

Vejamos o ponto 1. A estratégia dos autores é associar os usos ideológicos do ubuntu a uma "narrativa de retorno". Aqui deve-se abrir um parêntese para entender o que alguns dos autores que participam do debate em torno do ubuntu entendem a partir dessa expressão, e porque a associam ao ubuntu. Para Eliastam (2015) -, o

desejo de encontrar algo exclusivamente africano sobre o qual construir sociedades africanas pós-coloniais ou pós-conflitos não é único. Como os países africanos emergiram do domínio colonial e tentaram transformar suas sociedades, isso muitas vezes incluiu tentativas de retornar a algo do passado que é considerado nobre ou digno. Gade (2011) observa que essas narrativas de retorno tendem a dividir a história em três fases: a era pré-colonial que muitas vezes é concebida como um momento de harmonia quase perfeita e de prosperidade; uma segunda fase em que pessoas de fora roubam os recursos, a dignidade e a cultura do povo africano; e uma terceira fase de recuperação em que a dignidade e a cultura africanas são restauradas (2015, p. 1-2).

\section{Matolino e Kwindingwi seguem argumentação} semelhante para denunciar o uso do ubuntu como ideologia, voltada para uma "era dourada" mítica que, além de nunca haver existido, não encontra conexão com a contemporaneidade:
O que temos em mente aqui tem a ver com a interpretação dessas narrativas como representativas do autêntico modo de ser africano. Assim, o argumento que temos em mente é o seguinte: os defensores da narrativa de retorno partem do pressuposto de que as narrativas que eles oferecem são uma representação autêntica da vida africana. Por isso eles concluem que as narrativas são desejáveis em si mesmas. No entanto, curiosamente, os defensores de qualquer forma de retorno parecem ter, através de sua defesa, eliminado a possibilidade de outras interpretações de modos de ser africanos que poderiam estar em discrepância com sua narrativa preferida. O principal problema com essa visão, em nossa opinião, é que ela entende a vida africana como monolítica tanto em sua interpretação quanto em como ela é vivida. Parece não só haver um consenso sobre o que é importante para os africanos e no seu pensamento, mas também um consenso sobre o valor e no que uma vida útil deve consistir. Naturalmente, tal posição deve ser vista com suspeita por alguns motivos. Em primeiro lugar, ela torna os africanos - ou em suas condições originais ou em sua posição atual - incapazes de um pensamento individual ou dissidente. Em segundo lugar, em sua busca por um particular modo de ser africano idealizado em particular, ela faz da vida africana algo hegemônico. Em terceiro lugar, ela parece se tornar tradicionalista com o intuito de ser tradicionalista, pois limita sua defesa a uma narrativa de retorno sem prestar atenção em como outras dinâmicas poderiam moldar e dirigir a vida africana atual (MATOLINO, KWINDINGWI, 2013, p. 199).

Quanto ao ponto 2, os autores argumentam que o ubuntu dependeria de comunidades pequenas, coesas e indiferenciadas, relativamente subdesenvolvidas, que fossem atravessadas pela solidariedade associada ao espírito do ubuntu. Sem comunalismo não há o ubuntu. As transformações das sociedades africanas tornaram o conceito desconectado das possibilidades de sua realização. De todo modo, essa impossibilidade não constitui um problema para os autores. Pelo contrário, o problema estava efetivamente naquelas comunidades tradicionais, notórias por sua aversão a estranhos, por sua intolerância a ideias divergentes e por sua

\footnotetext{
9 O debate não se manteve apenas entre os contendores originais. Na mesma revista, pode-se encontrar mais dois desdobramentos. Em "The end of ubuntu or its beginning in Matolino-Kwindingwi-Metz debate: An exercise in conversational philosophy" IO fim do ubuntu ou o seu início no debate Matolino-Kwindingwi-Metz: um exercício de filosofia da conversação"], de 2016, Jonathan O. Chimakonam aponta problemas na argumentação de ambos os lados da contenda e propõe alternativamente não uma restauração do ubuntu, mas sua reinvenção. Em "Is it the end or just the beginning of ubuntu? Response to Matolino and Kwindingwi in view of Metz's rebuttal" [E o fim ou apenas o começo do ubuntu? Resposta a Matolino e Kwindingwi tendo em vista a refutação de Metz"], de 2017. Mojalefa L. J. Koenane e Cyril-Mary Pius Olatunji refutam as posições de Matolino e Kwindingwi, argumentando que seu ponto de chegada do fim do ubuntu é determinado pelo seu ponto de partida de que ubuntu é uma "narrativa de retorno", suposição que os autores deste artigo procuram desmontar. Optei por me ater apenas aos artigos que estabeleceram inicialmente o debate, por questões de espaço e para não estender demais a argumentação com o risco de cansar o leitor em demasia. Vale acrescentar que uma busca restrita a South African Journal of Philosophy registra 79 artigos que fazem referência a ubuntu entre 2001 e 2020.
} 
valorização das relações de sangue para o reconhecimento do outro: "estar comprometido com os valores do ubuntu é estar comprometido com a exclusão de outros valores" (MATOLINO, KWINDINGWI, 2013, p. 202). Finalmente, para Matolino e Kwindingwi os defensores do ubuntu falham em separar ética de metafísica:

Os africanos são adeptos do ubuntu porque existe algo de africano neles que os orienta para o ubuntu? Ou são africanos porque são adeptos do ubuntu? Nossa opinião é que essa interação entre ética e metafísica é problemática, uma vez que tende a ofuscar o que o ubuntu deveria ser. Argumentamos que qualquer das escolhas não ajuda muito o defensor do ubuntu. A primeira alegação de que os africanos são metafisicamente orientados para o ubuntu é desacreditada e não merece muito apoio. A segunda alegação de que o ubuntu faz de alguém africano é patentemente falsa. [...] ser africano pode ser qualquer coisa sem necessariamente se pensar que isso tem que estar de acordo com os ditames do ubuntu. Não é implausivel sugerir que existem modos de ser africano que são inconsistentes ou contrastam com o ubuntu (2013 p. 204).

Em seguida, mesmo sem que o mencionassem explicitamente, Metz (2014) elaborou uma resposta aos autores, por entender que aquelas criticas eram em grande medida direcionadas a ele - já que Metz vem se tornando recentemente o principal proponente do ubuntu como base para uma teoria moral contemporânea. No artigo, ele procura demonstrar a insuficiência das considerações de Matolino e Kwindingwi, além de fornecer razões para acreditar que o ubuntu enquanto teoria ética tem muito a dizer sobre como os indivíduos e as instituições devem ser no século XXI. Quanto ao primeiro ponto, Metz afirma ser irrelevante para suas pretensões o debate em torno do ubuntu como uma "narrativa de retorno". Se o conceito vier algum dia a assumir essa função ideológica negativa, não será em função do debate acadêmico em torno do tema (que segundo Metz é ignorado pelas elites políticas africanas). A intenção de Metz então é defender a validade do conceito como base ética para a ação. Para construir esse segundo ponto, o autor elenca uma série de exemplos de experiências e ações positivas presentes na vida sul-africana contemporânea que estariam relacionadas ao ubuntu, associadas a valores de solidariedade, colaboração, associativismo e justiça. E pergunta:

\begin{abstract}
Caro leitor, os exemplos acima despertam seu interesse? Eles merecem não apenas mais reflexão ética, mas também investigação psico-sócio-política para ver se eles seriam praticamente factiveis? Eles merecem ser testados em programas-piloto para ver se são bem-sucedidos? Se você respondeu "sim" a estas perguntas, então você concorda comigo que o ubuntu está longe de estar no fim. Está apenas começando, no sentido de estar agora em uma posição fantástica para afastar modos de vida indesejáveis com os quais ele tem sido associado, como sexismo e conservadorismo, e incorporar os insights da ciência, os beneficios da tecnologia e, mais geralmente, as facetas desejáveis da modernidade (METZ, 2014, p. 71).
\end{abstract}

Por fim, Matolino insiste, em sua tréplica, no arcaísmo e passadismo do ubuntu. Afirma mais claramente que considera a proposta de Metz utópica - e de um tipo de utopia conservadora, semelhante a muitas outras já tentadas na África com resultados nefastos:

\begin{abstract}
A defesa utópica de Metz do ubuntu afeta consideravelmente sua posição. [...] o tipo de utopia de Metz não é novo nem promissor no continente africano. Baseando-se em casos bem conhecidos e documentados de utopias passadas fracassadas, eu alerto Metz contra este movimento. [...] sua aprovação cega da democracia consensual como suporte para a eficácia do ubuntu na África moderna trai seu pensamento, como conservador ou seletivo (2015, p. 214).
\end{abstract}

Para Matolino, se Metz reconhece que ubuntu pode vir a ser utilizado como "narrativa de retorno", isso enfraquece a sua posição: por que voltar a um tema que pode causar tantos males, já comprovados historicamente? Matolino ataca no texto o comunalismo presente naquelas narrativas e no ubuntu, e procura associar a forma como Metz propõe a aplicação do ubuntu à África do Sul contemporânea com projetos "estatistas", "totalitários", "de partido único". É neste momento que Matolino expõe mais claramente suas motivações:

Este pensamento só é defensável dentro de uma determinada escola de pensamento. Esta escola de pensamento é aquela que pensa ser possivel ter uma vida comum e é realmente do interesse das pessoas perseguir uma vida comum. Esta escola de pensamento é conservadora em sua perspectiva política, já que interpreta a vida como monolítica e busca minimizar as diferenças (2015, p. 222). 
Adicionalmente, para Matolino o ubuntu não poderia ser entendido como uma teoria ético-moral a ser definida academicamente. Se assim fosse, estaria aberta a uma pluralidade de interpretações concorrentes, de acordo com as preferências e interesses de cada acadêmico e o debate filosófico não permitiria definir qual sentido é o mais correto, permitindo com isso que o ubuntu fosse qualquer coisa para qualquer um. Se ubuntu era algo endógeno aos "indigenas africanos subsaarianos" (como reconhecido por quase todos os seus defensores, inclusive Metz), então ele só poderia possuir um único sentido a ser investigado. Do modo desenvolvido por Metz - Matolino afirma -, ubuntu só poderia ser então a interpretação pessoal de Metz do que é ubuntu - mais precisamente, a sua própria ética informada por seus próprios valores.

Ainda assim, segundo Matolino, Metz seguiria tendo que responder de que modo considera ubuntu intrínseco ao negro-africano - algo que segundo Matolino estaria pressuposto em sua formulação, mas que (em justiça a Metz) não transparece em qualquer de seus trabalhos. Mais precisamente, como o ubuntu poderia ter se transportado das comunidades africanas tradicionais para a Joanesburgo contemporânea. Resumidamente, o argumento de Matolino é de que ubuntu só poderia ser considerado viável contemporaneamente com base em dois argumentos errôneos: a) enquanto "narrativa de retorno", um tradicionalismo, errado porque todas essas "ideologias" fracassaram; ou b) como um "essencialismo", errado porque se trata de uma posição que não é mais cientificamente defensável.

\section{Considerações finais}

Mas será que defender a validade do ubuntu implica necessariamente em "tradicionalismo" e em "essencialismo", como os seus detratores afirmam? Quanto à primeira crítica recorrente (a de tradicionalismo), pode-se argumentar que elementos do ubuntu seguem vigentes (adaptados ou ressignificados) na contemporaneidade, como a maioria de seus defensores afirma. Este não é o espaço para procurar comprovar a validade dessa argumentação, mas se efetivamente o ubuntu segue, em algum sentido, vigente, não se trataria então de uma "narrativa de retorno", um arcaísmo, um tradicionalismo, um reacionarismo. Considerar valores originários e ancestrais como elementos para sustentar modos de agir alternativos à modernidade implica evidentemente numa crítica ao individualismo, ao consumismo, ao capitalismo. Mas não necessariamente num retorno a um passado pré-moderno: pode se constituir como base para um futuro alternativo à modernidade.

Deve-se notar que qualquer forma de comunitarismo ou comunalismo é entendida em chave negativa por autores críticos do ubuntu, como explicitado na tréplica de Matolino a Metz. Trata-se da típica denúncia dos defensores da comunidade como "românticos" passadistas ("reacionários"), ou como coletivistas ("comunistas") - em ambos os casos, atravessados por práticas e visões de mundo pretensamente "autoritárias". A partir de uma equivocada dicotomia que associa individualismo com liberdade e modernidade, e comunalismo com autoritarismo e pré-modernidade, como boa parte dos autores críticos do ubuntu faz, nosso conceito ficaria numa situação difícil.

Defendo que a associação do ubuntu e de um modo geral da África à "tradição" e ao "passado" tem um forte sabor "eurocêntrico". Associar ubuntu a passado é o mesmo que conectá-lo com "atraso". Nessa chave, efetivamente ele só poderia ser entendido como a defesa de um retorno ao passado. A sociedade tradicional e o ubuntu são tratados como sinônimos, os "valores tradicionais" não cabem na modernidade liberal e no "Ocidente" e deles devem ser excluidos. Ora, o ubuntu se associa a uma concepção não ocidental de tempo, a noção circular de tempo que sobrepõe no mesmo espaço ancestrais, viventes e não nascidos (além de uma concepção integrada da humanidade à natureza). Para dialogar honestamente com ele, deve-se abandonar concepções progressistas, evolucionistas de tempo - em particular as que implicam em teleologias da história. É aí que se concentra boa parte de seu potencial crítico à modernidade. Ademais, argumenta-se diversas vezes que o 
ubuntu seguiria vigente no presente. Se assim for, também se prestaria a servir como base ético-moral para os aferrados a concepções modernas de temporalidade.

Assim, retomando o debate entre Matolino e Kwindingwi e Metz, argumento que o ubuntu pode ter vigência na modernidade, como defendido por Metz. Trata-se de uma reelaboração da ideia de "ser-sendo" (be-ing), que não precisa ter conexão direta com o que o ubuntu foi. Até porque não sabemos exatamente o que ubuntu foi, se é que foi especificamente alguma coisa em algum momento. O mais provável é que, mais precisamente, o termo ubuntu remeta a uma miríade de relações, crenças e modos de vida vagamente "africanos" ou "bantu", presentes em sociedades mais ou menos comunais anteriores aos contatos com a modernidade (não apenas através do processo colonizador, mas também anterior a ele), e que sobrevivem parcialmente em seu interior. O ubuntu é um modo (poderia ter sido outro) de nomear o que é considerado por muitos como algo que foi superior no passado, e que foi destruido com o advento da modernidade - que nesse caso, convém recordar, significou guerra, conquista, opressão, dominação, escravidão e apartheid.

Se uma das principais criticas que se pode fazer ao ubuntu é que em boa parte de suas versões ele entenderia a África como una e como estática (e desse modo essencialista e a-histórica), pode-se depreender o mesmo problema dos argumentos de seus detratores. Esses, ao considerarem ubuntu como algo exterior à modernidade, mais precisamente anterior a ela, o associam automaticamente a algo inferior, a partir de uma concepção teleológica de história implícita à visão explicitamente liberal desses críticos. ${ }^{10}$

Assim chegamos à segunda critica recorrente entre os detratores do ubuntu (a de seu essencialismo). O ubuntu, em algumas de suas formulações nacionalistas ou pan-africanistas, efetivamente pode envolver "essencialismos" (uma das criticas centrais também de Matolino e Kwindingwi). Defender que haveria um modo de ser conectado a uma "alma" africana, à raça negra ou a qualquer metafisica é uma formulação que não teria mais lugar num debate acadêmico respeitável. Muitas vezes o ubuntu foi entendido como algo essencialmente negro-africano, desde suas primeiras aparições no século XIX. Mas argumentos racialistas, biológicos nunca estão explícitos na literatura contemporânea sobre o ubuntu. Caberia explicitar então se ele é especificamente negro-africano por estar relacionado a uma "cultura negro-africana", ou a caracteristicas econômico-sociais, ou a tradições. E, definida qual seria essa conexão, se ele poderia vir a servir de inspiração para além de seu lugar de origem.

É razoável supor que essa vastidão denominada "ubuntu" remete efetivamente a modos de vida, a visões de mundo manifestadas numa pluralidade de sociedades africanas, tanto no passado do continente, quanto sobreviventes de forma adaptada ou em potência nas sociedades africanas contemporâneas. Essa posição, que pode ser sustentada a partir de argumentos históricos, econômicos, sociológicos, antropológicos, políticos, culturalistas, filosóficos, é perfeitamente aceitável, na medida em que o debate em torno da "unidade" ou "fragmentação" africana encontra-se ainda em aberto, na academia e nas reflexões do próprio continente e da diáspora. Não há necessariamente "essencialismo" nesse tipo de argumentação - apenas a defesa de que, para além das (evidentes) diversidades, haveria elementos comuns a unificar o continente (e a diáspora) no passado, no presente e potencialmente no futuro. Mas isso não resolve o problema em torno das possibilidades de se "ubuntizar" o mundo para além de seu lugar de origem, ou colocado de outra forma, de se universalizar o ubuntu.

Argumento pela superação de quaisquer essencialismos na análise do conceito de ubuntu, ou seja, pela necessidade de complexificar os posicionamentos de alguns dos apoiadores e dos detratores do ubuntu. Como afirmei acima, ubun-

10 Anthony Oyowe, ao criticar as tentativas de Metz de construir uma filosofia moral baseada no ubuntu que agregue a liberdade individual e os direitos humanos, é mais explícito nesse ponto: "Talvez para sociedades mais industrializadas e globalizadas, nas quais os ideais liberais de liberdade e direitos humanos são de importância central na formação da moralidade pública, uma ética do ubuntu possa exercer somente um papel muito mais restrito do que tinha nas sociedades africanas pré-industriais" (2013, p. 124) 
tu pode ser entendido como uma reelaboração contemporânea, como algo que guarda relação vagamente com elementos do passado, e ninguém sabe exatamente o que o ubuntu foi - ou o que "foram" os ubuntus. Como observou Kimmerle,

reduzir o ubuntu à frase "eu sou porque nós somos", como tantas vezes acontece, também é muito esquemático. Este provérbio não pode ser considerado uma contrapartida africana direta do dito de Descartes "cogito ergo sum". As coisas são mais diferenciadas. Temos que levar em conta que o "eu", ou a pessoa, está se tornando cada vez mais importante na ontologia africana também. Por sua vez, no Ocidente uma filosofia do "nós" não é impossivel e surgiu como um forte fluxo filosófico chamado "comunitarismo", que enfatiza o significado da comunidade. Assim, temos que olhar com mais detalhes para o impacto filosófico do ubuntu e do espirito comunitário africano, a fim de descobrir o que eles podem significar no mundo de hoje (2006, p. 81).

Desse modo, ainda que envolva mitos, e que remeta a "raízes", a "origens" e a "ancestralidades", o ubuntu não precisa constituir uma "narrativa de retorno" passadista e reacionária. No sentido adotado por boa parte de seus apoiadores políticos e por quase todos os acadêmicos que desenvolvem o conceito (por exemplo, para ficar com os mais importantes, respectivamente Tutu e Ramose), o ubuntu é inspiração para projetos transformadores, voltados para o futuro. É pensado como uma crítica, por vezes radical, ao individualismo, à reificação, ao materialismo e à falta de solidariedade da modernidade.

Pode ser que o potencial do ubuntu esteja exatamente na crença compartilhada em torno de sua existência. Ou seja, em seu potencial narrativo - não propriamente como "narrativa de retorno" a um passado idealizado, mas enquanto "narrativa de futuro". Para o psicólogo e filósofo sul-africano Dirk Louw (2010), no sentido de repensar o ubuntu em seu caráter emancipatório. O seu trabalho exemplifica com precisão o que estou afirmando aqui. O autor parte do pressuposto de que,

embora se possa duvidar da existência do ubuntu como uma realidade plenamente vivida, dificilmente pode-se negar sua existência como um conceito proeminente, narrativa ou mito na África, e certamente no Sul da África. Chamar a ética do ubuntu de mito não é negar sua "verdade factual", embora a palavra seja frequentemente usada neste sentido. A palavra "mito" como usada aqui se refere à ética do ubuntu como uma história duradoura que - independentemente de sua "verdade factual" - inspira moralmente e revela o significado (ou seja, o valor, a relevância ou a significância) da vida para aqueles que participam dela, isto é, aqueles que contribuem para contá-la e recontá-la (2010, p. 2).

Na medida em que constitui antes de tudo uma narrativa, ubuntu só pode ser entendido como a

rearticulação de uma ética antiga, inspirada pelo que é percebido como seus melhores atributos. Sua meta não é servir como uma cortina de fumaça para as anomalias e atrocidades das sociedades africanas tradicionais. [...] Tampouco significa um chamado para retornar aos valores, orientações e práticas das vilas pré-coloniais do Sul da África. É em qualquer sentido impossivel restaurar a versão "original" do ubuntu. Nossos entendimentos do ubuntu podem ser no máximo reconstruções inovadoras, inevitavelmente coloridas por nossos valores, crenças e perspectivas (pós-)modernas. Neste sentido, qualquer tentativa de responder à questão "o que é ubuntu?" (leia-se: "como ele foi primeiramente formulado?"), deveria ser evitada. Apesar de uma reflexão sobre ubuntu dificilmente poder ignorar noções herdadas sobre ele, seguramente a questão mais importante deve ser: "como ubuntu deveria ser entendido e utilizado para o bem comum de todos os africanos, e de todo o mundo?" (2010, p. 8).

Nesse sentido, o ubuntu remete a um passado mais ou menos mitificado, e pode assumir os mais diversos usos político-ideológicos. Essa "mitificação" não envolve um mal em si mesmo, ao contrário do que Matolino e Kwindingwi insistem em afirmar. A mitificação é central em qualquer narrativa política, em qualquer construção identitária, na motivação para qualquer projeto de futuro, em qualquer "utopia". Assim, enquanto conceito político, ubuntu pode ser mais ainda que uma teoria moral no sentido proposto por Metz. Mais que uma ética, que um modo correto de agir em sociedade, ubuntu aponta para a possibilidade de toda uma organização social alternativa. Ele reconfigura as relações temporais e espaciais típicas da modernidade, podendo implicar numa superação da tricotomia passado/presente/ futuro e das dicotomias individuo/sociedade e humanidade/natureza - todas elas construções 
artificiais. É nesses elementos criticos à modernidade que ele poderia vir a inspirar projetos de transformação para além do sul da África e do espaço das culturas bantu.

\section{Referências}

BELL, Richard H. Understanding African Philosophy. A Cross-Cultural Approach to Classical and Contemporary Issues. Nova lorque: Routledge, 2002.

BURTON, Mary Ingouville. The Truth and Reconciliation Commission. Joanesburgo: Jacana, 2016.

CHIMAKONAM, Jonathan O. The end of ubuntu or its beginning in Matolino-Kwindingwi-Metz debate: An exercise in conversational philosophy. South African Journal of Philosophy, [S. I.], v. 35, n. 2, p. 224-234, 2016.

ELIASTAM, John. Exploring ubuntu discourse in South Africa: loss, liminality and hope. Verbum et Ecclesia, Pretoria, v. 36, n. 2, p. 1-8, 2015.

GADE, Christian. The Historical Development of the Written Discourses on Ubuntu. South African Journal of Philosophy, [S. I.], v. 30, n. 3. p. 303-329, 2011.

HAILEY, John. Ubuntu: A Literature Review. Londres: Tutu Foundation, 2008

KASHINDI, Jean-Bosco Kakozi. Ubuntu como vivencia del humanismo africano bantú. Devenires, Morelia, v. XIV, n. 27, p. 210-225, 2013

KEEVY, Ilze. Ubuntu versus the core values of the South African Constitution. Journal for Juridical Science, Bloemfontein, v. 34, n. 2, p. 19-58, 2009.

KIMMERLE, Heinz. Prophecies and Protests. Ubuntu and Communalism in African Philosophy and Art. In: HEUVEL, Henk van den; MANGALISO, Mzamo; BUNT, Lisa van de (ed.). Prophecies and Protest. Ubuntu in Glocal Management. Amsterdam: Rozenberg Pub.; Pretoria: Unisa Press, 2006. p. 79-92.

KOENANE, Mojalefa L. J.; OLATUNJI, Cyril-Mary Pius. Is it the end or just the beginning of ubuntu? Response to Matolino and Kwindingwi in view of Metz's rebuttal. South African Journal of Philosophy, [S. I.], v. 36, n. 2, p. 263-277, 2017.

LOUW, Dirk. Power sharing and the challenge of ubuntu ethics. In: DU TOIT, C. W. (ed.). Power sharing and African democracy: interdisciplinary perspectives. Pretoria: Research Institute for Theology and Religion: Unisa Press, 2010. p. 121-137.

MANGENA, Fainos. "Hunhu/Ubuntu in the Traditional Thought of Southern Africa". Internet Encyclopedia of Philosophy, 2016. Disponivel em: www.iep.utm.edu/ hunhu/. Acesso em: 28 abr. 2021.

MATOLINO, Bernard. A response to Metz's reply on the end of ubuntu. South African Journal of Philosophy. IS. l.], v. 34, n. 2, p. 214-225, 2015.
MATOLINO, Bernard; KWINDINGWI, Wenceslaus. The end of ubuntu. South African Journal of Philosophy, IS. I.], v. 32, n. 2, p. 197-205, 2013

MAWERE, Munyaradzi, VAN STAM, Gertjan. Ubuntu/ Unhu as Communal Love: Critical Reflections on the Sociology of Ubuntu and Communal Life in sub-Saharan Africa. In: MAWERE, Munyaradzi; MARONGWE, gonidzashe. (ed.). Politics, Violence and Conflict Management in Africa: Envisioning Transformation, Peace and Unity in the Twenty-First Century. Bamenda: Langaa RPCIG, 2016. p. 287-304

METZ, Thaddeus. Just the beginning for ubuntu: reply to Matolino and Kwindingwi. South African Journal of Philosophy, [S. I.], v. 33, n. 1, p. 65-72, 2014.

MUNYAKA, Mluleki, MOTLHABI, Mokgethi. Ubuntu and its socio-moral significance. In: MUROVE, Munyaradzi Felix (ed.). African Ethics: An Anthology of Comparative and Applied Ethics. Scottsville: University of KwaZulu-Natal Press, 2009. p. 63-84.

MUROVE, Munyaradzi Felix. An African Environmental Ethic Based on the Concepts of Ukama and Ubuntu. In: MUROVE, Munyaradzi Felix (ed.). African Ethics: An Anthology of Comparative and Applied Ethics. Scottsville: University of KwaZulu-Natal Press, 2009. p. 315-332.

OYOWE, Anthony O. Strange bedfellows: Rethinking ubuntu and human rights in South Africa. African Human Rights Law Journal, Pretoria, n. 13, p. 1-22, 2013.

RAMOSE, Mogobe. The philosophy of ubuntu and ubuntu as a philosophy. In: COETZEE, Pieter; ROUX, Abraham (ed.). The African Philosophy Reader. 2. ed. Nova lorque Routledge, 2003a. p. 270-280.

RAMOSE, Mogobe. The ethics of ubuntu. In: COETZEE, Pieter; ROUX, Abraham (eds.). The African Philosophy Reader. 2. ed. Nova lorque: Routledge, 2003b. p. 379-387.

RAMOSE, Mogobe. I conquer, therefore I am the sovereign: Reflections upon sovereignty, constitutionalism, and democracy in Zimbabwe and South Africa. In: COETZEE, Pieter; ROUX, Abraham(ed.). The African Philosophy Reader. 2. ed. Nova lorque: Routledge, 2003c. p. 543-589.

REPUBLIC OF SOUTH AFRICA. Constitution of the Republic of South Africa, 1993. Disponivel em: https://Www. gov.za/documents/constitution/constitution-republic-south-africa-act-200-1993\#. Acesso em: 28 abr. 2021. www1.chr.up.ac.za/chr_old/indigenous/documents/ South\%20Africa/Legislation/Constitution\%200f\%20 South\%20Africa\%201993.pdf

SHUTTE, Augustine. Politics and the Ethic of Ubuntu. In MUROVE, Munyaradzi Felix (ed.). African Ethics: An Anthology of Comparative and Applied Ethics. Scottsville: University of KwaZulu-Natal Press, 2009. p. 375-390.

SILVA, Fabricio Pereira da. Comparando conceitos da periferia global: por uma tipologia dos sentidos de ubuntu e de bem viver. Izquierdas, Santiago, n. 49, p. 3524-3544, 2020.

SILVA, Fabricio Pereira da. Em busca da comunidade Caminhos do pensamento crítico na periferia global. São Paulo: Elefante, 2021 (no prelo). 
TAMBULASI, Richard, KAYUNI, Happy. Ubuntu and Democratic Good Governance in Malawi: A Case Study. In: MUROVE, Munyaradzi Felix (ed.). African Ethics: An Anthology of Comparative and Applied Ethics. Scottsville: University of KwaZulu-Natal Press, 2009. p. 427-440.

TEMPELS, Placide. La Philoshophie Bantoue. Élisabethville [Lubumbashi]: Lovania, 1945.

TUTU, Desmond. No Future Without Forgiveness. Londres: Random House, 1999.

\section{Fabricio Pereira da Silva}

Doutor em Ciência Política pelo Instituto Universitário de Pesquisas do Rio de Janeiro da Universidade Candido Mendes (IUPERJ/UCAM), no Rio de Janeiro, RJ, Brasil; professor de Ciência Politica da Universidade Federal do Estado do Rio de Janeiro (UNIRIO), no Rio de Janeiro, RJ, Brasil.

\section{Endereço para correspondência}

Fabricio Pereira da Silva

Universidade Federal do Estado do Rio de Janeiro

Escola de Ciência Política

R. Voluntários da Pátria, 107

Botafogo, 22270-000

Rio de Janeiro, RJ, Brasil

Os textos deste artigo foram revisados pela Poá Comunicação e submetidos para validação do autor antes da publicação. 